\title{
ABLATION RATES ON THE CEILING OF A SNOW TUNNEL OVER A STREAM
}

by

\author{
TAKammo UEMatsu
}

Japan Weather Association, Kita-1, Nishi-23

Chuo-ku, Sapporo, Japan 064

\section{ABSTRACT}

A snow tunnel is of ten formed between the water surface of a small stream and the base of a snow cover in snowy areas. Observations made in northern Japan revealed that the amount of snow ablated at the ceiling of the snow tunnel ranged widely from $1.3-50$ $\mathrm{kg} / \mathrm{m}^{2}$.d. This amount was calculated using heat transfer method; assuming that the ceiling was ablated only by the flux of heat from stream water, the amounts observed and calculated were found consistent.

\section{INTRODUCTION}

In winter most small streams are covered with thick snow in northern Japan. A snow tunnel is of ten formed between the surface of stream water and the base of a snow cover. It is mainly the flux of heat from the water that melts the ceiling of such a snow tunnel. The amount of snow ablated at the ceiling was directly observed and compared with an amount calculated by heat transfer method.

\section{RESULTS AND DISCUSSION}

Observations were carried out at three sites in Hokkaido, Japan: 1) Mt. Uenshiridake 2) Moshiri and 3) Bankei, the first two in northern Hokkaido and the third near Sapporo.

1) In a snow tunnel (height: 1-3 m) formed under a snow patch in a narrow valley of Mt. Uenshiridake, ablation rates were observed using snow stakes for one-week periods in July and August 1976, together with air temperature and wind speed. During this period the mean ablation rate estimated was $50 \mathrm{~kg} / \mathrm{m}^{2}$.d. The stream temperature was $6-14^{\circ} \mathrm{C}$.

2) Small streams are entirely covered with snow in winter at Moshiri. About twice a month from December 1976 to January 1977, coal ash was scattered on the surface of the snow cover on a small stream as a marking of the surface. The location of the ash line exposed on a vertical cross section of the snow cover,

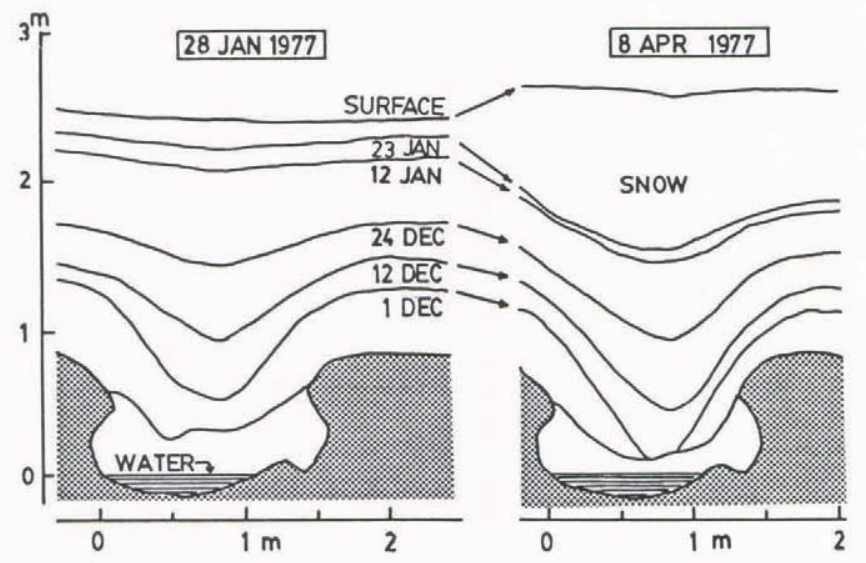

Fig.1. Vertical cross section of a snow cover on 28 January 1977 and 8 April 1977. and the height of the tunnel, were measured on 28 January 1977 and 8 April 1977. Figure 1 shows the vertical cross section of the snow cover on both days. Using the measured values, the ablation rate during this period was estimated. The method of estimation was as follows. It was assumed that the ceiling went down by the same amount as ash scattered on 12 December 1976 went down between 28 January and 8 April, (dashed line in Figure 2). The amount of ablation between 28 January and 8 April was considered to be the difference between the actual height of ceiling on 8 April and the estimated height. The ablation rate during this period was estimated to be about $1.3 \mathrm{~kg} / \mathrm{m}^{2} \cdot \mathrm{d}$, the stream temperature being about $1.1^{\circ} \mathrm{C}$.

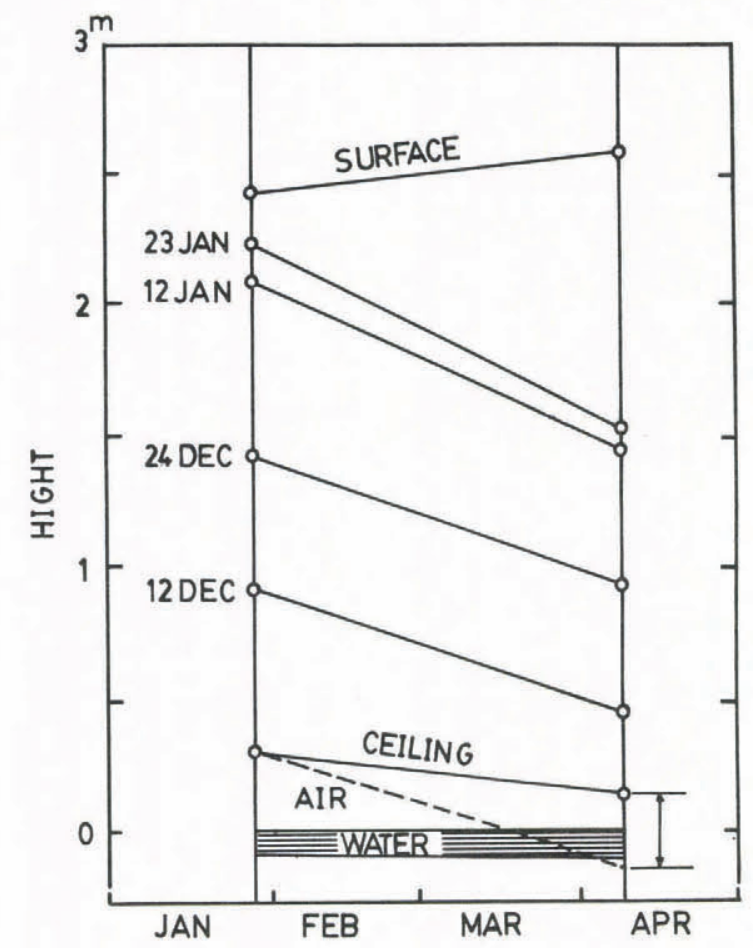

Fig.2. Schematic representation for ablation estimation. Symbol o represents the location of ash in the center vertical line of a vertical cross section of the snow cover, corresponding to the dates in Fig.1.

3) From a similar observation carried out from 15 February to 8 March 1981 at a small stream at Bankei, the ablation rate during this period was estimated to be about $1.5 \mathrm{~kg} / \mathrm{m}^{2} \cdot \mathrm{d}$, the stream temperature ranging from $1.3-1.6^{\circ} \mathrm{C}$.

The ablation rates observed above were compared with rates calculated on the basis of heat flux from the water surface of the stream as follows:

The calculated rate $R_{a}$ was deduced as

$\mathrm{R}_{\mathrm{a}}=\mathrm{q} / \mathrm{L}_{\mathrm{i}}$ 
Uematsu: Ablation in snow tunnel

When $\mathrm{q}$ is the heat flux from the stream water to the ceiling of a snow tunnel (if the conductivity heat flux flows into the snow, it must be subtracted from q) and $L_{i}$ is the latent heat of ice in fusion. First, $a$ can be expressed as

$$
\mathrm{q}=\mathrm{q}_{\mathrm{R}}+\mathrm{q}_{\mathrm{S}}+\mathrm{q}_{\mathrm{L}}
$$

where $q_{R}$ is the net radiative heat flux, $q_{s}$ is the sensible heat flux and $q_{L}$ is the latent heat flux. Then, $q_{R}$ can be expressed as

$$
\mathrm{q}_{\mathrm{R}}=\sigma\left(\mathrm{T}_{\mathrm{w}}^{4}-\mathrm{T}_{\mathrm{S}}^{4}\right) \text {, }
$$

where $\sigma$ is the Stefan-Boltzmann constant, $T_{w}$ is the water temperature in $K$ and $T_{S}$ is the temperature of the ceiling of the snow tunnel in $K$.

Next, $\mathrm{q}_{\mathrm{S}}$ can be expressed as

$$
\mathrm{q}_{\mathrm{S}}=\lambda \Delta \mathrm{T} \text {, }
$$

where $\lambda$ is the heat transfer coefficient and $\Delta T=T_{w}$ $T_{s}$. The value of $\lambda$ is related to the height of the tunnel, $\Delta \mathrm{T}$ and the surface velocity of the stream, which is so small that it can reasonably be neglected.

The following describes how $\lambda$ is obtained: Silveston (1958) made an experiment on heat transfer through horizontal fluid layers heated from below, whereby he discovered that convection occurred when Rayleigh number was larger than 1700.

The Rayleigh number $\mathrm{N}_{\mathrm{Ra}}$ is defined as

$$
\mathrm{N}_{\mathrm{Ra}} \equiv \frac{\mathrm{g} \beta \mathrm{H}^{3} \Delta \mathrm{T}}{\mathrm{v} \alpha}
$$

where $\mathrm{g}$ is the gravity, $\boldsymbol{\beta}$ is the coefficient of expansion, $v$ is the kinematic viscosity, $\alpha$ is the thermal diffusivity, $\mathrm{H}$ is the layer depth (the height of a snow tunnel).

Then, O'Tool and Silveston (1961) expressed the following formula from the above data:

$$
\mathrm{Nu}=0.104\left(\mathrm{~N}_{\mathrm{Ra}}\right)^{0.305}\left(\mathrm{~N}_{\mathrm{Pr}}\right)^{0.084}
$$

where $\mathrm{Nu}$ is the Nusselt number and $\mathrm{N}_{\mathrm{Pr}}$ is the Prantle number. The Nusselt number is defined as

$$
\mathrm{Nu} \equiv \frac{\lambda H}{\mathrm{k}}
$$

where $k$ is the conductivity and the Prantle number is defined as

$$
\mathrm{N}_{\mathrm{Pr}} \equiv \frac{\mathrm{v}}{\alpha}
$$

Formula 6 can be used only when $\mathrm{N}_{\mathrm{Ra}}$ ranged from $10^{5}$ - $10^{9}$, which covered all the calculation cases in the present experiment.

Consequently $\mathrm{Nu}$ can be determined from 5,6, and 7 , and $\lambda$ can be determined from 8 and the Nusselt number. For example, when water temperature is $5.7^{\circ} \mathrm{C}$ and the ceiling height is $1.25 \mathrm{~m}$, we find $\mathrm{Nu}=63$ and $\lambda=1.21\left(\mathrm{~W} / \mathrm{m}^{2} \cdot \mathrm{K}\right)$.

Finally, $\mathrm{q}_{\mathrm{L}}$ can be expressed as

$$
\mathrm{q}_{L}=\mathrm{L} \cdot \lambda_{D}\left[\frac{\mathrm{M}}{\mathrm{R}}\right]\left[\frac{\mathrm{Pw}}{\mathrm{Tw}}-\frac{\mathrm{Ps}}{\mathrm{Ts}}\right] \text {, }
$$

where $L$ is the latent heat of water, $\lambda_{D}$ is the mass transfer coefficient, $M$ is the molecular weight of water, $R$ is the gas constant, and $P_{w}$ and $P_{S}$ are the saturated water vapor pressures at the temperatures of the water and ceiling, respectively. The value of $\lambda_{D}$ can be determined in similar way as the value of $\lambda$, when it is assumed that the Sherwood number is equal to the Nusselt number.

Table 1 shows the ablation rates estimated from the observed data and calculated rates in $\mathrm{Mt}$. Uenshiridake, Moshiri and Bankei. The rates in Mt. Uenshiridake were calculated for 2-3 July and 2-3 August 1976, because the data were complete for both
TABLE 1. OBSERVED AND CALCULATED ABLATION RATES

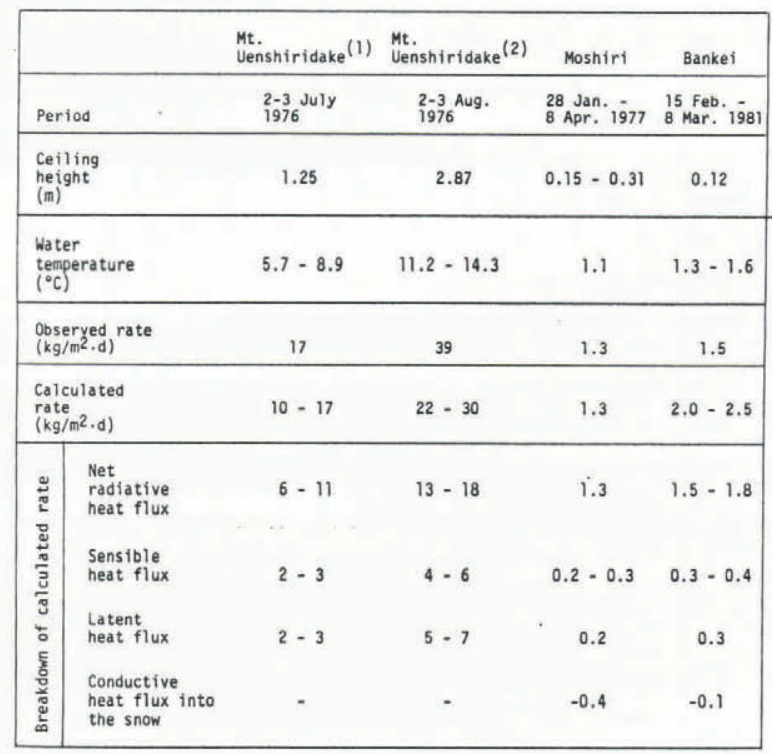

periods. Table 1 also shows the ablation rates by the heat fluxes $\mathrm{q}_{R}, \mathrm{q}_{\mathrm{S}}$, and $\mathrm{q}_{\mathrm{L}}$. The dominant component of them was $q_{R}$ in these four calculation cases, as shown in Table 1. The ablation rates estimated from the observed data were consistent with the calculated rates. However, when the ceiling was lower than about $1 \mathrm{~m}$, the observed rates were smaller than the estimated rates. When the ceiling was higher than $1 \mathrm{~m}$, the relationship was reversed. The outside air which flowed into the tunnel was considered to be an important cause of an increase in ablation rate.

\section{CONCLUDING REMARKS}

In all four cases, the amount of snow observed to have ablated at the ceiling of a snow tunnel over a stream ranged widely because of differences in tunnel height, water temperature and perhaps the flow of outside air into the tunnel. Calculation of ablation using the heat transfer method gave results consistent with observations; adjustments made for the outside air flow into the tunnel may account for the discrepancies.

\section{ACKNOWLEDGEMENTS}

The author expresses his best thanks to $\mathrm{Dr} D$ Kobayashi and Dr K Kojima, Institute of Low Temperature Science, Hokkaido University, for helpful suggestions in observation and analysis.

\section{REFERENCES}

Naruse R, Takahashi S, Uematsu T, Nishimura K, Suizi S, Okano T, Nishimura H, Kikuchi T 1976 [Glaciological studies of a snowpatch in Mt. Uenshiridake, Hokkaido.] Low Temperature Science A-34: 147-162 (in Japanese with English summary)

O'Toole J L, Silveston P L 1961 Correlation of convective heat transfer in confined horizontal layers. Chemical Engineering Progress Symposium 57: 81-86

Silveston P L 1958 Warmedurchgang in waagerechten Flussigkeitsschichten. Forsh. Ing. Wes. 24: 29-32, 59-69

Uematsu T 1982 [Heat budget of a small river covered with snow in winter]. Suion No Kenkyu 26(2): 2-6 (in Japanese) 